\title{
Catching the Wave: Are Biology Graduate Students on Board with Evidence-Based Teaching?
}

\author{
Emma C. Goodwin, Jane N. Cao, Miles Fletcher, Justin L. Flaiban, \\ and Erin E. Shortlidge*
}

Biology Department, Portland State University, Portland, OR 97201

\begin{abstract}
Graduate students hold a critical role in responding to national calls for increased adoption of evidence-based teaching (EBT) in undergraduate classrooms, as they not only serve as teaching assistants, but also represent the pool from which future faculty will emerge. Through interviews with 32 biology graduate students from 25 institutions nationwide, we sought to understand the progress these graduate students are making in adopting EBT through qualitative exploration of their perceptions of and experiences with both EBT and instructional professional development. Initial inductive content analysis of interview transcripts guided the holistic placement of participants within stages of Rogers's diffusions of innovations model, which we use as a theoretical framework to describe the progress of EBT adoption. We found that most graduate students in our sample are aware of and value EBT, but only $37.5 \%$ have implemented EBT. Many who were progressing toward EBT adoption had sought out supplementary instructional experiences beyond the requirements of their programs, and $72 \%$ perceived an institutional lack of support for teaching-related professional development opportunities. These data indicate that, while many graduate students are already engaged with the movement to adopt EBT, graduate training programs should emphasize increasing access to quality training in EBT strategies.
\end{abstract}

\section{INTRODUCTION}

Two principal actions are required to respond to the national calls for increasing retention and building equity in undergraduate science classrooms (American Association for the Advancement of Science, 2011; President's Council of Advisors on Science and Technology, 2012). First, we must determine and evaluate the classroom strategies that can be used to reach these goals, and second, we must facilitate the widespread dissemination of these strategies into undergraduate classrooms. Much progress has been made to develop evidence-based teaching (EBT) strategies that can be used to better reach our students. These strategies are typically student centered and based on research that tests their effectiveness (e.g., clickers, Socratic discussion, case studies; Handelsman et al., 2004; Tanner, 2013). For those who might be interested in adopting EBT, there is little doubt left that these active-learning strategies are working for many students. In addition to reports of affective gains such as positive impacts on student motivation, selfesteem, and attitude (Springer et al., 1999; Michael, 2006; Cleveland et al., 2017), a meta-analysis of 225 individual studies found that active learning increases examination scores and decreases failure rates (Freeman et al., 2014). As we continue to develop and evaluate active-learning strategies, significant attention must also be given to efforts to increase dissemination of EBT into undergraduate classrooms.

In many biology departments, graduate student teaching assistants (TAs) teach laboratory and discussion sections for high-enrollment introductory courses-in a survey given to 34 research universities, $91 \%$ reported that biology graduate students are responsible for most of the laboratory instruction (Sundberg et al., 2005). Because graduate student TAs may end up with more undergraduate face time than faculty,
Marilyne Stains, Monitoring Editor

Submitted Dec 26, 2017; Revised Apr 11, 2018 Accepted Apr 18, 2018

CBE Life Sci Educ September 1, 2018 17:ar43 DOI:10.1187/cbe.17-12-0281

*Address correspondence to: Erin E. Shortlidge (eshortlidge(apdx.edu).

(c) 2018 E. C. Goodwin et al. CBE-Life Sciences Education @ 2018 The American Society for Cell Biology. This article is distributed by The American Society for Cell Biology under license from the author(s). It is available to the public under an Attribution-Noncommercial-Share Alike 3.0 Unported Creative Commons License (http://creativecommons.org/licenses/ by-nc-sa/3.0)

"ASCB®" and "The American Society for Cell Biology $\AA^{\prime \prime}$ are registered trademarks of The American Society for Cell Biology. 
and graduate students represent the pool of future faculty, there have been proposals advocating for improvement in pedagogical training for graduate students (Rushin et al., 1997; Austin, 2002; Gardner and Jones, 2011; Kendall et al., 2013; Reeves et al., 2016). A framework for TA instructional professional development by Reeves et al. (2016) describes how TAs' pedagogical knowledge, attitudes, and beliefs impact their teaching practices, which in turn directly impacts undergraduate students. Further, there is a suite of contextual variables such as the institution type, the training TAs have been exposed to, and the pre-existing teaching experience, attitudes, and career aspirations of TAs (Reeves et al., 2016) that influence how a TA operates in the classroom. Understanding graduate students' experiences of, attitudes toward, and perceptions of EBT will build a better understanding of the variables that impact graduate student adoption of EBT.

\section{Instructor Adoption of EBT}

To date, studies on instructor adoption of new teaching strategies have focused on faculty rather than graduate students. Simply sharing the "evidence" behind EBT does not seem to be enough to incite adoption of EBT among science faculty; for example, interviews with physics faculty revealed a mistrust of physics education research and education researchers (Henderson and Dancy, 2008). Similarly, biology faculty prioritize their personal experiences of success over education research as rationale for sustained adoption of case study teaching (Andrews and Lemons, 2015). This indicates that faculty likely need more structure and support to successfully adopt EBTinforming instructors that specific strategies "work" is likely insufficient.

Further, the propensity toward adoption of EBT is likely highly context specific. A study of science faculty at one research institution revealed that faculty across scientific disciplines have high awareness of specific EBT strategies, but levels of interest and rates of adoption of EBT strategies vary greatly among faculty in different departments (Lund and Stains, 2015). Such differences were thought to be caused by differences in departments, learning environments, personal experiences, and attitudes toward teaching. Given the different contextual influences faculty and graduate students are exposed to, it would be negligent to assume that graduate students approach EBT with the same attitudes, beliefs, and goals as faculty. It is therefore vitally important to understand not only how faculty perceive EBT, but how graduate students perceive it as well, if we are to best facilitate adoption of EBT in the newest generation of biology faculty.

\section{Potential Factors Impacting Graduate Student Adoption of EBT}

The professional identity of scientists often tends to value and prioritize research over teaching, which could be a significant barrier to adoption of EBT (Brownell and Tanner, 2012). While many faculty have already formed their professional identities as scientists, graduate students are only beginning to develop their professional identities and may therefore be more receptive to making changes to their teaching practices. However, graduate students also have less autonomy in the classroom than faculty instructors - a 2002 case study of graduate TAs at a single UK university found that TAs were dissatisfied with their lack of freedom in their teaching (Park and Ramos, 2002). While their dissatisfaction with their lack of freedom indicates the possibility that graduate students could desire more flexibility to experiment in teaching, the perception that they do not have the autonomy to adapt the material or alter their teaching style could hinder EBT adoption.

Even if graduate students have some level of autonomy in the classroom, adoption of EBT strategies, as for faculty, is likely to be largely context dependent and subject to influences from departments, advisors, and perceptions of their own role as graduate students. In contrast to current faculty, who may have had limited personal experiences with EBT as undergraduates, graduate students may already be familiar with EBT from their time as undergraduates, which could impact their attitudes toward EBT. For example, interviews with six chemistry TAs revealed that their own frustrating experiences as undergraduates in inquiry courses led them to be hesitant that inquiry-based instruction was suitable for their students (Kurdziel et al., 2003). Indeed, most research on TA experiences with using EBT have focused specifically on inquiry-based laboratory instruction and have found that graduate students, at least initially, struggle and are frustrated with inquiry-based instruction (Kurdziel et al., 2003; Gormally et al., 2016; Mutambuki and Schwartz, 2018). This may be due to a struggle to align the teaching method with their perceptions of effective teachingfor example, graduate students who prioritize the importance of content knowledge may have difficulty valuing inquiry-style teaching (Kurdziel et al., 2003; Luft et al., 2004). These values and perceptions of EBT strategies will impact graduate students' approaches to teaching and their decisions to adopt EBT.

To better understand whether and how graduate students, specifically those in the life sciences, are gaining experiences with EBT strategies, and whether they are interested in and prepared to adopt EBT strategies as a regular part of their teaching, we conducted a qualitative study. We specifically sought to learn

1. What types of teaching experiences or training are graduate students expected or required to participate in? Do graduate students perceive that their programs support them in gaining training and experience using EBT strategies?

2. Do graduate students know about EBT strategies and the shift in academic culture that values EBT?

3. Are graduate students adopting or interested in adopting EBT strategies, and are there factors that correspond with EBT adoption?

\section{THEORETICAL FRAMEWORK}

Rogers's diffusion of innovations (DOI) model has been used to describe faculty adoption of EBT (Henderson and Dancy, 2008; Henderson et al., 2012; Andrews and Lemons, 2015; Lund and Stains, 2015), shedding light upon where the barriers to EBT adoption lie. DOI is a theoretical framework first published in 1962 that describes the process a motivated individual or organization takes in deciding to adopt an innovation (Rogers, 2003). The model was initially developed to describe the adoption of agricultural innovations by farmers (Rogers, 2003) and has since been used to describe the adoption (or lack of adoption) of many innovations ranging from information systems (Bhattacherjee, 2001) to evidence-based practices in healthcare (Kajermo et al., 1998; Dobbins et al., 2002). According to the 
DOI framework, individuals adopting an innovation go through several steps: first, they gain knowledge of an innovation (stage 1, Knowledge), then develop a positive or negative attitude toward that innovation (stage 2, Persuasion). Next, they engage in activities that lead to a decision on whether or not to implement the innovation themselves (stage 3, Decision). The individual then implements the innovation (stage 4, Implementation), and finally reflects on whether or not to continue use of the innovation (stage 5, Confirmation). These steps can happen over years or rapidly, and they are not strictly linear-for example, an individual could engage in a training session (Decision), during which he or she might both learn about an innovation (Knowledge) and form an opinion (Persuasion).

Because we started with little knowledge of the teaching-related perceptions and experiences of current biology graduate students, we chose to use qualitative research methods to begin to gain an in-depth understanding of our subjects, far beyond what could be accomplished through a survey instrument (Creswell, 2009). Given the admirable prior usage of the DOI model and the nature of our data, we chose to also use the DOI framework to identify the stages of our study participants in adoption of EBT. Using this lens, we can delve into the perceptions and experiences of graduate students who both successfully adopt and fail to adopt EBT. The nature of the model will also allow us to gain insights into where graduate student adoption of EBT is commonly delayed.

\section{METHODS}

\section{Participant Recruitment}

We recruited interview participants through a link at the end of the Life Sciences Graduate Student Survey (LSGSS). The LSGSS was an online survey that aimed to gain an understanding of life science graduate student experiences with EBT strategies. We sent the survey to graduate students nationwide in the summer of 2016 through various listservs and snowball sampling. At the end of the survey, participants were given the option to follow a link to a new form allowing them to volunteer their contact information for a possible follow-up interview. We invited all 148 participants who provided their contact information to participate in interviews and received 38 responses to our interview request. Of these volunteers, 32 signed up for and completed the interview process. The information in the LSGSS and the interviews discussed in this study were not linked; therefore, we derived all information presented in this study directly from the interviews, and online survey results (Shortlidge and Eddy, 2018) are presented elsewhere. We used nationwide survey data of life science graduate students and recent doctoral recipients from National Science Foundation surveys (Survey of Earned Doctorates [NSF, 2016a]; Survey of Graduate Students and Postdoctorates in Science and Engineering [NSF, 2016b]) to identify demographics of U.S. life science graduate students. We then used chi-square goodness-of-fit tests to calculate whether the reported race, gender, and university type of our participants was representative of graduate students nationwide. The Portland State Internal Review Board approved this study (protocol \#163844).

\section{Interview Design and Execution}

The interview protocol consisted of 17 questions primarily intended to explore participants' experiences with and perceptions of EBT strategies. Participants were asked about professional development they received within their graduate programs and their self-efficacy as instructors. The interview protocol concluded with 10 optional demographic questions (Supplemental Material). All participants were interviewed via Skype by a single researcher (M.F.). Before beginning the interviews, the research team discussed the purpose of each question and conducted pilot interviews with several graduate students in the life sciences who were not connected to the study. We used these validity efforts to confirm that the questions were appropriately designed to prompt productive discussion of graduate student experiences and to verify that graduate students interpreted the questions in the manner intended. The interviews were semistructured (Cohen and Crabtree, 2006); therefore, the interviewer could deviate from the scripted interview to ask follow-up questions for clarification or elaboration. The interviews lasted 30 minutes on average, were audio-recorded, transcribed verbatim (Rev.com, San Francisco), and deidentified before data analysis.

\section{Data Analysis}

Three researchers (E.C.G., M.F., E.E.S.) read all of the interview transcripts and independently created lists of the different perceptions, attitudes, and opinions that arose from participant responses throughout the interviews. Together, we discussed our initial findings from the interviews and developed a comprehensive preliminary list of "codes." These codes were short, descriptive phrases that could be used to describe particular perceptions, attitudes, or opinions expressed by the participants throughout the transcript text. As different questions evoked diverse responses from participants, the developed codes were not necessarily linked to responses to specific interview questions. To refine our list of codes and confirm that we independently understood how to use each code, we methodically reread four interview transcripts that we felt represented diverse participant perspectives and independently made notations of where we felt the codes should be applied. We then convened to discuss our coding decisions and reflected as a group on the ways in which specific codes were either useful or unclear and/or redundant. Using the notes from the group discussion, a single researcher (E.C.G.) reduced and reorganized the list of codes into a preliminary codebook. Two researchers (E.C.G., M.F.) then used the codebook to independently code two to three transcripts at a time, and we reconvened between each set to discuss and further define and reduce codes in our codebook that were unclear to us. We intentionally selected transcripts that reflected diverse perspectives to use for this process, and in total, we used 14 transcripts in the process of refining our codebook. We considered the codebook to be robust once two of us were able to use the final version to code six (19\%) of the transcripts with an average $83 \%$ interrater reliability (Madill et al., 2000). A single researcher (E.C.G.) then used the final codebook to recode all of the transcripts that had not yet been coded with the final codebook, conferring with another researcher (M.F.) when the coding designation was ambiguous or difficult to discern. All coding with the final codebook was conducted using (NVivo version 11.4, QSR International). Participant information that was quantitative or categorical (e.g., year in program, type of teaching training) was recorded directly into a spreadsheet. 
Analysis of coding considered only the presence or absence of specific themes within each participant's interview, not the frequency with which a single participant expressed a particular theme.

For a final check of coding accuracy, two additional researchers (J.N.C., J.L.F.) uninvolved in the initial coding or the codebook development audited the data derived from the interview transcripts. To prepare for this audit, the researchers read all of the interview transcripts, were debriefed in detail on the project, and were trained to use the codebook. We recorded all resulting data for each individual participant, which included categorical variables (e.g., institution type), numeric data (e.g., number of courses taught), and whether the participant made a statement pertaining to each code (presence/absence of code) in a master spreadsheet. From this spreadsheet, we randomly generated a list of cells to audit (10\% of the data; specifically, 500 of 5056 cells), which were divided between the auditors, who worked independently to confirm the presence or absence of selected data by rereading the original transcripts. For example, if the randomly selected cell showed that the participant had made a statement represented by a particular code in the codebook, those data were verified through reading the text of the corresponding transcript and identifying whether that participant did indeed make at least one statement that could be coded under the specific theme. In nearly all instances, auditors agreed with the initial coding.

During coding, it became apparent that there were overarching themes in the attitudes and beliefs of the participants that, while frequently associated with specific codes, were not always sufficiently described by the codes. The primary coder and two auditors (E.C.G., J.N.C., J.L.F.) reread all of the interview transcripts and discussed which participants exhibited specific attitudes or beliefs on the basis of the entire interview text. We used these holistic targeted evaluations to elucidate each participants' placement within the DOI model: the entire research team discussed how participants would be placed into the DOI model, and final placements were determined through iterative and collaborative discussions involving at least three researchers. To understand whether a graduate student's placement along the DOI model could potentially be influenced by his or her career goals, field of study, or time in program, we informally observed trends in these categories once all participants were placed within the DOI model; however, due to the low sample size and the qualitative nature of this study, we do not present statistical differences among groups of participants.

\section{RESULTS}

\section{Participant Demographics}

In total, 32 life science graduate students from 25 different institutions across the continental United States were interviewed. The majority (69\%) of the participants attended highest research activity (R1) universities, with the remainder from higher research institutions (R2, 19\%), moderate research institutions (R3, 9\%), and special focus institutions (3\%) Carnegie Classification of Institutions of Higher Education [Indiana University Center for Postsecondary Research, 2017]). Participants ranged in age from 23 to 40 years old (mean $=28.6$ years, $\mathrm{SD}=3.5$ ). The majority of the participants identified as female (59\%); 75\% as white/Caucasian,
13\% Asian American, 9\% Latina/o, and 3\% identified as Indian (South Asian). There were no significant differences (chi-square goodness-of-fit, all $p>0.05$ ) between our sample's reported demographics (gender, race/ethnicity, and university type) and those reported in the NSF Survey of Earned Doctorates and the Survey of Graduate Students and Postdoctorates in Science and Engineering (NSF, 2016a,b).

\section{Graduate Student Status and Professional Goals}

Overall, 97\% of our participants were PhD students, and all participants were at least in the second year of their graduate programs (mean year in program $=4.3, \mathrm{SD}=1.3$ ). Participants were conducting graduate research on topics that spanned subdisciplines of biology: $37.5 \%$ molecular or cellular biology, genetics, or immunology; 34\% ecology; 16\% evolutionary biology; and $12.5 \%$ biology education research (BER). Additionally, $9 \%$ of the students who had a non-BER research focus selfreported participating to some extent in an education research project in addition to their primary research projects. We considered that graduate students who had participated in BER may have a biased awareness of EBT strategies that would not be representative of life science graduate students in general. Upon reflection and discussion of the interview transcripts and based on statistical tests for differences among BER students and/or those who had participated in education research, the research team determined that their experiences did not differ from those of their peers who had not been involved in education research. Therefore, these data include graduate students studying both basic biology research and BER.

Participants reported being interested in pursuing a varied set of professional goals: $28 \%$ hoped to obtain primarily research positions in academia; $31 \%$ explicitly stated they want to obtain an academic position that would allow them to balance both research and teaching responsibilities; and 19\% were interested in primarily teaching positions. The remaining $22 \%$ described plans to leave academia for careers in government, industry, or science communication and outreach.

\section{Graduate Students Receive Little Support for Instructional Training}

To address our first research question, we report on our participants' experiences with teaching, mandatory TA training, and their perceptions regarding their program's support for their instructional training. Our participants had diverse experiences in their roles as TAs. The majority were experienced TAs - 19\% had one term of TA experience, 44\% had between two and five terms experience, and $31 \%$ had between six and 14 terms of experience as a TA. Only $6 \%$ of the participants had never been a TA before. Most of the participants had experience teaching lab sections (72\%) and/or recitation sections (63\%); however, $19 \%$ had experience as the instructor of record for a course. A few participants did not provide a specific count of the number of terms of TA experience they had; thus, the reported terms of TA experience are conservative estimates based on the information provided. For example, one participant explained,

I've taught a lot of different classes. I've taught Plant Ecology, Introductory Biology, Genetics, and right now I'm teaching a Botany class.-Male, third-year ecology PhD student 
A

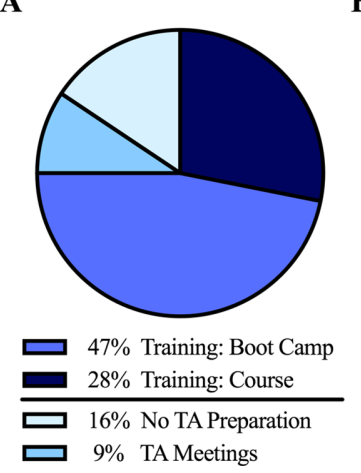

B

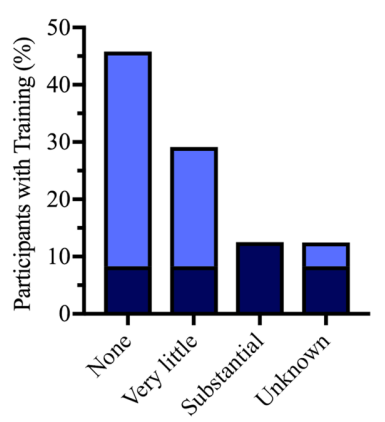

Amount of Training in Instructional Strategies

FIGURE 1. Most participants had some type of formal teaching training, although few of those with formal training had been trained in instructional strategies. (A) Types of teaching training that graduate students report receiving to date in their training programs. (B) Reported amount of training in instructional strategies for those who participated in mandatory formal training courses or boot camp.

This student did not specify whether he had taught multiple iterations of any of the four classes listed; therefore, we recorded that he only had four terms of TA experience.

Most Graduate Students Participate in Some Form of Mandatory TA Training. We felt it was important to understand what man datory training our participants had received from their universities with regard to their teaching responsibilities, and whether their training had included information about EBT strategies. Only $28 \%$ of our participants described taking a required TA training course that lasted a full term, while $47 \%$ described participating in a boot camp-style TA training either before or concurrently with their first term as a teaching assistant (Figure 1A).

While we were encouraged that $75 \%$ of our participants had received some formal mandatory training through a course or boot camp, $46 \%$ of those who had received formal training reported that they were not given any instruction in the use of any teaching strategies (Figure 1B). An additional 29\% of those with formal training reported receiving very little training in instructional strategies-described by one participant through the following statement:

It's mostly not really about teaching strategies but mostly, how to identify sexual harassment and those sorts of things. They do tell you some of the strategies out there, but they don't really emphasize them that much.-Male, fifth-year ecology PhD student

Only $12.5 \%$ of graduate students reported that they had received substantial training in the use of various instructional strategies in their formal mandatory training, for example,

We also had an opportunity to present for 5 minutes to practice teaching and then also a period later on where it was 15 minutes practice teaching ... It's kind of neat to see other people teach. We also talked about some teaching strategies and active-learning strategies.-Female, second-year cellular biology PhD student

Graduate Students Perceive a Lack of Support to Develop Instructional Skills. In total, $72 \%$ of our participants discussed the various deficits in their opportunities to develop their instructional skills within their programs. Some graduate students (28\%) additionally highlighted the disparity between the lack of these opportunities and their departments' proclaimed value for teaching (Table 1).

The most commonly described deficit of instructional development was limited instructional training (44\%). Although some of these participants explained that they did not have access to any instructional training, many who perceived limited instructional training simply felt that the training they did receive was insufficient. Others who perceived limited instructional training at their institution were aware of optional training, but described barriers that prevented them from taking advantage of these opportunities-they had no incentives to attend, or even felt pressure from peers or advisors to not spend time on instructional training at the cost of forfeiting time that should be spent on research. For example,

I'm not sure how many students actually take those optional (teaching) courses but perhaps (the department should) advertise those a little bit more. I personally don't know anybody who's actually taken those courses yet.-Male, second-year ecology PhD student

Similarly, participants who expressed that they had limited opportunities to teach (34\%) both described logistical limitations (primarily limited teaching opportunities at their institutions) or a lack of support from peers and advisors toward pursuing teaching opportunities simply for the sake of gaining experience as an instructor, rather than the necessity of receiving financial support from a TA-ship:

I really wanted to do more teaching and basically everybody told me to stop doing that ... it would be nice if there was a little more support for people who wanted to teach more.Female, fourth-year evolutionary biology PhD student

One-third of the participants (all who had at least some opportunities to teach) perceived a deficit of instructional professional development, reporting they had limited opportunities to expand their teaching role (34\%). A couple of these participants repeatedly taught the same class and felt that the challenge of teaching a different type of course (i.e., course content, a majors vs. nonmajors class, or anything other than a lab section) would further develop their instructional skills. Other participants in this group expressed that a standard TA-ship, in which they were provided with materials and constrained expectations for what needs to happen in their classroom, is insufficient for fully preparing them as instructors:

For me a huge (challenge) is going to be actually teaching a full course ... I really need to be able to put all the pieces together. Including the teaching strategies, developing lesson plans, doing the assessments, because that I've never done before, putting it all together.-Female, fifth-year molecular biology $\mathrm{PhD}$ student 
TABLE 1. Participant perceptions regarding lack of support for teaching from their graduate training programs

\begin{tabular}{|c|c|c|c|}
\hline \multicolumn{2}{|c|}{$\begin{array}{l}\text { Theme/subtheme: } \% \text { of } \\
\text { participants }(n=32)\end{array}$} & Description & Representative quotes \\
\hline \multirow{2}{*}{ 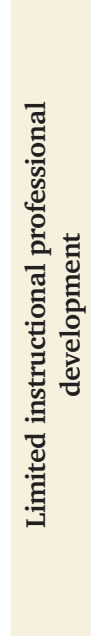 } & $\begin{array}{l}\text { Limited instructional } \\
\text { training: } 44 \%\end{array}$ & $\begin{array}{l}\text { Describes lack of instructional } \\
\text { training opportunities or lack of } \\
\text { incentive to participate }\end{array}$ & $\begin{array}{l}\text { "Because in most faculty positions, you do have to do some teaching, so I } \\
\text { would encourage my department to maybe offer mandatory teaching } \\
\text { workshops, because they're (currently) not mandatory. If you have a } \\
\text { lot of lab work, or classes, or things that you have to do, then you } \\
\text { never prioritize those nonmandatory workshops."-Male, fifth-year } \\
\text { ecology PhD student }\end{array}$ \\
\hline & $\begin{array}{l}\text { Limited opportunities } \\
\text { to expand teaching } \\
\text { role: } 34 \%\end{array}$ & $\begin{array}{l}\text { Expresses desire for more autonomy } \\
\text { or responsibility in the } \\
\text { classroom }\end{array}$ & $\begin{array}{l}\text { "[I would like a change from] being told 'This is a professor's course and } \\
\text { here's the material, go teach it' ... If I could have taken more of an } \\
\text { active step to maybe be an instructor of record or designing my own } \\
\text { course, or cooperatively designing a section of a course. Then } \\
\text { carrying that out. I think that would be the most valuable thing for } \\
\text { me right now."-Male, fifth-year ecology PhD student }\end{array}$ \\
\hline \multicolumn{2}{|c|}{$\begin{array}{l}\text { Institutional lip service } \\
\text { toward teaching: } 28 \%\end{array}$} & $\begin{array}{l}\text { Describe situations in which they } \\
\text { perceive their institutions or } \\
\text { departments do not value or } \\
\text { invest in instructional training } \\
\text { or teaching, even though they } \\
\text { may state otherwise }\end{array}$ & $\begin{array}{l}\text { "Not to be too negative about it, but I think there's a lot of language } \\
\text { about valuing teaching and valuing science outreach and communi- } \\
\text { cation and having good TAs in our department, but there's also a lot } \\
\text { of pressure to make TAing as time-efficient as possible and to make it } \\
\text { more about us instead of our students."-Male, fifth-year ecology } \\
\text { PhD student }\end{array}$ \\
\hline
\end{tabular}

These graduate students desired the opportunities to develop teaching materials, to experience giving large lectures, or to fully design and teach an undergraduate course.

A smaller but compelling group of graduate students described situations in which they perceived that their institution provided lip service toward valuing teaching (28\%), explaining or giving examples in which their institution attempted to give the appearance of valuing teaching, but in practice did not sufficiently support graduate students in learning how to teach. For example, some students described that their institutions technically provided institutional training, but that it was a highly insufficient effort to actually develop their instructional skills. Some of these students expressed incredulity that their programs expected them to develop instructional skills in their training, due to either the lack of informative instructional skills emphasized in the training, or the minimal nature of the training (one as short as 15 minutes: "I think there was [training] ... It was like a 15-minute, couple of slides at our grad student orientation. That was it" [Female, fifth-year ecology PhD student]). Other participants perceived negative attitudes from their peers and faculty within their departments toward the instructional opportunities offered and explained that many in their department considered instructional training activities were "blow-off" or "useless" pursuits.

\section{Graduate Students Are Aware of the Academic Culture Shift Favoring EBT}

Perhaps surprisingly, in investigating our second research question, we found that our participants exhibited a high level of awareness and appreciation for EBT strategies (Table 2). In total, $84 \%$ of our sample conveyed that they value EBT strategies. Many of these participants demonstrated their value of EBT strategies both by explaining why they find evidence-based strategies to be more effective through their experiences either as a student or an instructor and by simply describing the active-learning strategies that they preferred over didactic lecture.

Demonstrating their interest in and commitment to gaining instructional experience, 59\% of participants sought out nonmandatory teaching opportunities. These participants found opportunities to attend teaching-centric workshops or classes, to give guest lectures, and to teach extra classes or develop course materials for the purpose of gaining instructional experience. Many of these participants described these nonmandatory opportunities as the experiences that allowed them to further learn and practice implementation of EBT strategies.

Graduate students were also aware of the increasing value that universities and education research places on EBT, which we describe as participants perceiving the changing landscape of academia in teaching (78\%). Graduate students who perceived this shift in academia described observing a trend in increased use of EBT and perceived that universities are increasingly expecting EBT to be used in their classrooms:

It seems like even at larger state schools, there's a greater focus on student-centered learning, active-learning, nontraditional classrooms, group work in a more transformative way. It's become much more important at a variety of institutions.Male, fifth-year ecology PhD student

A smaller subset of this group (47\% of participants) fell into a group that explicitly exhibited self-awareness of their own role in this shift toward valuing EBT strategies (part of the changing landscape of academia). These participants repeatedly used first-person language that conveyed personal accountability for 
TABLE 2. Participant perceptions related to EBT

\begin{tabular}{|c|c|c|}
\hline $\begin{array}{l}\text { Theme: } \% \text { of } \\
\text { participants }(n=32)\end{array}$ & Description & Example quotes \\
\hline $\begin{array}{l}\text { Value EBT strategies: } \\
\quad 84 \%\end{array}$ & $\begin{array}{l}\text { Express value for EBT by indicating } \\
\text { that active-learning techniques } \\
\text { made sense with their personal } \\
\text { philosophy of learning or uses } \\
\text { their personal experiences as a } \\
\text { student or teacher to describe the } \\
\text { practical value of EBT strategies }\end{array}$ & $\begin{array}{l}\text { "Your undergrad degree should be focused on you learning how to learn ... you } \\
\text { can't just passively receive this information."-Female, third-year biology } \\
\text { education PhD student } \\
\text { "Different topics come up reflecting backgrounds of each student, what they } \\
\text { have learned or what they have experienced, and I think that gives the } \\
\text { opportunity for us to kind of dig the topic a little bit deeper."-Female, } \\
\text { fourth-year molecular/cellular biology PhD student }\end{array}$ \\
\hline $\begin{array}{l}\text { Seek out teaching } \\
\text { opportunities: } 59 \%\end{array}$ & $\begin{array}{l}\text { Describes going beyond mandatory } \\
\text { requirements to gain experiences } \\
\text { in instructional training or extra } \\
\text { teaching }\end{array}$ & $\begin{array}{l}\text { "Because I went out of my way, I got to learn about active learning and } \\
\text { technology in the classroom and all that, but at least in my experience, it's } \\
\text { not something you learn unless you actively try and go learn it."-Male, } \\
\text { fifth-year ecology PhD student } \\
\text { "I think people who love teaching and are excited about teaching don't want to } \\
\text { feel like they're doing a mediocre job. We have to take it upon ourselves to } \\
\text { seek out training. Those resources are totally there. It has to be driven by } \\
\text { graduate students."-Male, fifth-year ecology PhD student }\end{array}$ \\
\hline $\begin{array}{l}\text { Aware of changing } \\
\text { landscape of } \\
\text { academia in } \\
\text { teaching: } 78 \%\end{array}$ & $\begin{array}{l}\text { Displays a sense of awareness for the } \\
\text { shifting attitudes and expectations } \\
\text { toward teaching in academia }\end{array}$ & $\begin{array}{l}\text { "I know there has been a push toward that sort of active learning, because it's } \\
\text { supposed to get students a little bit more engaged than they would } \\
\text { otherwise be just sitting in a lecture room, listening to the professor."-Male, } \\
\text { third-year ecology PhD student } \\
\text { "I think you're going to have to have professors who want to be there and are } \\
\text { thinking about how to structure a class instead of finding someone who's } \\
\text { really good at their field and being like 'Well you know a lot about this, tell } \\
\text { people about it."--Female, sixth-year molecular/cellular biology PhD student }\end{array}$ \\
\hline $\begin{array}{l}\text { Part of the changing } \\
\text { landscape of } \\
\text { academia: } 47 \%\end{array}$ & $\begin{array}{l}\text { Use language or describe themselves } \\
\text { in ways that convey self-aware- } \\
\text { ness of their role in changing the } \\
\text { landscape of academia as it relates } \\
\text { to teaching }\end{array}$ & $\begin{array}{l}\text { "I'm trying to get away from the traditional lecture format. Instead of spewing } \\
\text { information at the students, really taking students' needs into account, } \\
\text { thinking about pedagogy and active learning ... My undergrad was more of } \\
\text { just show up, get lectured at for } 50 \text { minutes, and then take the test."-Male, } \\
\text { fifth-year ecology PhD student } \\
\text { "We started assessing our students more and kind of test them in what they } \\
\text { have learned and we've realized that it doesn't correlate with what we want } \\
\text { them to learn. There's this big disconnect in what we're doing and what } \\
\text { they're actually getting out of it."-Female, third-year evolutionary biology } \\
\text { master's student }\end{array}$ \\
\hline
\end{tabular}

promoting attitude shifts and adoption in favor of EBT strategies within their departments and fields. Further, these participants often described the specific changes they had made (or planned to make) to their own teaching to advance the use of EBT within their discipline or described specific interactions with their peers and/or actions they had taken within their departments in support and promotion of EBT adoption.

\section{Graduate Students Are Interested in Adopting EBT Strategies}

To address our third research question, we mapped the progress of graduate students in adopting EBT strategies using the DOI model. As we used our codebook to identify the major themes present in these interviews, we also were able to discern that certain themes and holistic trends correlated to groups of graduate students who were in different stages of the process of incorporating EBT strategies into their teaching philosophies. For each stage in the model, we mapped the proportion of the 32 participants who successfully "continue" through each stage and the proportion who fall out of the adoption process (Figure 2). Here, we describe characteristics of groups of participants who arrived at each stage of the model. For clarity, we will continue to use percentages to describe proportions of our total participants who fall into the different DOI stages, but proportions of small subgroups presenting specific characteristics within each DOI stage will be described numerically.

Stage 1. Knowledge: Most Graduate Students Know About $E B T$. Knowledge of an innovation is the stage when an individual learns of the existence of the innovation, which can be impacted by the individual's socioeconomic status, personality, communication behavior, and access to relevant communication channels (Rogers, 2003). For graduate students, communication channels that lead to knowledge of EBT strategies could include professional development events and courses, their research advisors, instructors and lab managers for the courses they TA in, and peers. Graduate students in our study exhibited a wide range in their level of knowledge of EBT strategies and were accustomed to an assortment of different terminology to describe EBT. We specifically asked students about their familiarity with student-centered teaching practices versus instructor-centered teaching practices (Supplemental Material), and for those who asked for a definition of student-centered teaching practices, we described the contrast between didactic lecturing versus putting more responsibility for learning on 


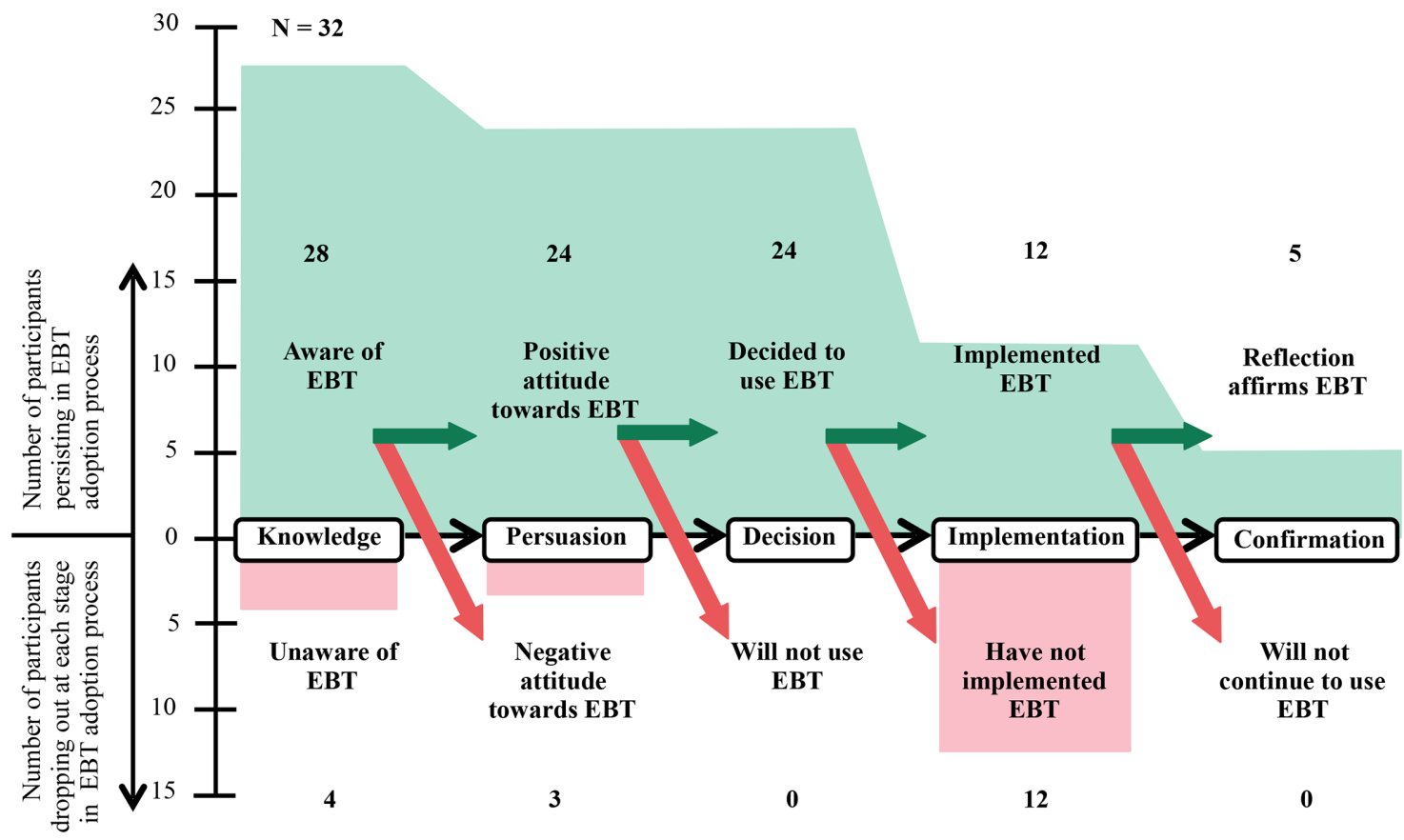

FIGURE 2. Path of graduate students through the DOI model toward adoption of EBT. The number of participants who demonstrated progression to each stage in the model are depicted above the $x$-axis (in green), while the number of participants who drop out at each stage in the model are depicted below the $x$-axis (in red). Some participants neither "drop out" or progress to the subsequent stage in the model-for example, while five of the 12 participants who had used EBT strategies progressed to the Confirmation stage, the remaining seven simply did not demonstrate significant reflection to either positively or negatively confirm their use of EBT strategies.

students through active-learning strategies. We considered participants who exhibited understanding of evidence-based strategies throughout their interviews to have Knowledge about EBT, for example,

Student-centered learning is the idea is that the students are taking a much more active role in their own education ... stuff like doing hands-on activities or doing the research on a particular topic or leading a discussion.-Female, fifth-year genetics PhD student

Participants who were unfamiliar with EBT strategies, even with the help of an explanation, stopped progressing toward adoption of EBT strategies at the Knowledge stage.

Most of our participants (87\%) had an accurate working definition of student-centered teaching (or active learning) and were, at minimum, familiar with at least one or two specific strategies. Nearly all of these participants who have knowledge of EBTs moved on to the second stage in the model, and only one participant remained at this stage in the modelthat student was aware of EBTs, but held an ambivalent attitude toward them.

Participants who dropped out at the Knowledge stage $(12.5 \%)$ lacked a clear conception of EBT strategies, even when prompted with definitions and/or examples, which prevented them from truly beginning the process of adopting EBT. Intriguingly, participants in this group did express some interest in the concept of engaging students beyond what would be expected in a purely didactic classroom. For example, one participant (male, third-year ecology $\mathrm{PhD}$ student) indicated a desire to design an "interactive" class but could not communicate how he would facilitate that:

Participant: With Introductory Biology, it's really much more of a lecture type setting, but I would try to make it to where it was a little bit interactive, when you were asking students questions.

Interviewer: Do you have ideas how you might facilitate that interaction?

Participant: I don't think I do specifically. For labs, I'll ask questions, and then it's ... Labs are always very much obviously interactive. I don't think I have so much of an idea for a classroom setting.

While their lack of awareness about EBT strategies prevented them from progressing through the model, it is encouraging that this group appears to be open to the idea of learning about EBT.

Stage 2. Persuasion: Most Graduate Students Have Positive Attitudes Toward EBT. At the Persuasion stage, graduate students formed a positive or negative attitude regarding the use of EBT strategies. All participants who had formed positive attitudes toward EBT strategies (75\%) progressed to the Decision stage of the DOI model. For example,

One of the shortcomings I see in our current way we do higher education in the sciences is so much of it is just canned stuff, where it's come in, do this lab, listen to this. Getting more 
active inquiry, working through things, working through problems, and actually seeing the process of science in action, I think would be a good thing for the field as a whole.-Male, fifth-year ecology $\mathrm{PhD}$ student

A few participants who were aware of EBT strategies had a negative attitude toward them (9\%), therefore dropping out of the process of adopting EBT strategies at the Persuasion stage (Figure 2). These students felt that there were opportunities within their departments to develop their teaching skills, but they were not interested in pursuing them:

I would say that I'm more prepared to be a research faculty member. I could do the teaching as well, but considering I've personally prepared myself to be a researcher, that's where it is. If I wanted to prepare myself to be a better teaching faculty member, I could have said to my advisor, "I want to TA every semester," which would have increased my experiences. I would have had that opportunity if I wanted to.-Male, fourthyear molecular biology $\mathrm{PhD}$ student

Unsurprisingly, participants with negative attitudes toward EBT strategies also unanimously did not think there would be much of a benefit toward learning about EBT:

I have those things that I took away from undergrad that I enjoyed, and the things I didn't enjoy. I feel like between a mesh of all that, I wouldn't change too much.-Male, second-year evolutionary biology $\mathrm{PhD}$ student

\section{Stage 3. Decision: Graduate Students with Positive Attitudes Toward EBT Plan to Implement EBT. Graduate students who progressed through the Decision stage toward EBT adoption described specific EBT strategies that they plan to use if they ever design their own undergraduate biology class:}

I've at least heard about [EBT strategies] and I think what I really want to do now is actually implement them.-Female, fifth-year genetics $\mathrm{PhD}$ student

Because all graduate students who had a positive attitude toward EBT strategies had decided to implement EBT strategies ( $75 \%$ of total), no students dropped out of the model at this stage.

Stage 4. Implementation: Most Graduate Students Have Not Implemented EBT. Graduate students who reached the Implementation stage described specific experiences in which they had chosen to implement one or more EBT strategies as an instructor. Of the $75 \%$ of graduate students who had decided to implement EBT strategies, half actually found opportunities to do so, while the other half had not yet implemented EBT, thereby dropping out of the model at this stage (Figure 2). For example,

I've unfortunately only after being a teaching assistant received instruction in evidence-based active-learning instruction. Just being aware of that, and of some of the instructors who use such methods has really changed my opinion about how a classroom should be run.-Female, fourth-year immunology $\mathrm{PhD}$ student
Because graduate students have variable access to TA-ships, and sometimes little control of the curriculum, it is inescapable that some graduate students do not have the opportunity to progress through the Implementation stage. Presumably for this reason, many of the participants who did not implement EBT seemed to have similar attitudes and perceptions as those who had actually implemented EBT. For example, both groups identified the potential benefits of EBT for undergraduate students, and they were aware of the changing landscape of academia (Table 2) that increasingly values effective undergraduate teaching.

Stage 5. Confirmation: Few Graduate Students Complete the Process of EBT Adoption. Not all graduate students who have implemented EBT have had opportunities and/or adequate guidance to reflect on their EBT experience to the extent to which they can confidently confirm that they are using strategies they would like to adopt into their permanent teaching repertoire. Despite this potentially unequal access to the Confirmation stage, we identified that $16 \%$ of our participants had reached this stage (Figure 2). The reflections of those who reached this stage positively affirmed their use of EBT strategies:

Personally, my most successful student-centered learning strategies usually revolve around class discussion, usually in sort of a think-pair-share, jigsaw sort of format and, then, taking that back out into a broader overall class discussion with me and with the students more or less leading it ... I think that it helps them develop, cognitively, beyond the early stages for their earlier years and up, their undergraduate experience. I would say that's probably my favorite tool, actually, Socratic method.-Male, sixth-year ecology PhD student

In addition to the reflective statements that defined the participants who were placed in the Confirmation stage, participants at this stage were highly metacognitive of their own role in the academic attitude shift toward teaching (part of the changing landscape of academia; Table 2).

We informally observed some trends in our collected data among groups of participants at different stages in the DOI model. Participants in all stages of the DOI model described limited instructional professional development opportunities (lack of TA training, opportunities to teach, or ability to increase their autonomy in the classroom; Table 1). However, four of the 12 students who had not implemented EBT had the perception that EBT was not possible in large classes, while only one of the participants who actually implemented EBT expressed this perception. None of the participants who dropped out of the DOI model in the early stages (Knowledge and Persuasion) had sought out nonmandatory instructional training or teaching experiences (seeks out teaching opportunities; Table 2). In contrast, participants who reached the Decision, Implementation, and Confirmation stages often did seek out nonmandatory teaching or training experiences. In a similar pattern, an increasingly higher proportion of participants in the Decision, Implementation, and Confirmation stages of the DOI model were aware of their role as part of the changing landscape of academia (Table 2). This suggests that whether or not graduate students use EBT may not be entirely controlled by their TA assignments and the circumstances of their programs, but also 
TABLE 3. Training experiences of participants at different stages in the DOI model

\begin{tabular}{|c|c|c|c|c|c|}
\hline \multirow[b]{2}{*}{ Characteristics } & \multicolumn{5}{|c|}{ Stages of the DOI model } \\
\hline & $\begin{array}{c}\text { Stopped at } \\
\text { knowledge } \\
(n=5)\end{array}$ & $\begin{array}{l}\text { Stopped at } \\
\text { persuasion } \\
\quad(n=3)\end{array}$ & $\begin{array}{c}\text { Have not } \\
\text { implemented } \\
(n=12)\end{array}$ & $\begin{array}{c}\text { Have } \\
\text { implemented } \\
(n=7)\end{array}$ & $\begin{array}{c}\text { Positively } \\
\text { confirmed } \\
(n=5)\end{array}$ \\
\hline Average year in program & $3( \pm 1 \mathrm{SD})$ & $3.7( \pm 1.5 \mathrm{SD})$ & $4.4( \pm 1.4 \mathrm{SD})$ & $4.9( \pm 0.9 \mathrm{SD})$ & $4.7( \pm 1.5 \mathrm{SD})$ \\
\hline Average number of terms as TA & $2( \pm 1.9 \mathrm{SD})$ & $2.7( \pm 1.5 \mathrm{SD})$ & $3.2( \pm 2.4 \mathrm{SD})$ & $7.4( \pm 5.1 \mathrm{SD})$ & $7.2( \pm 2.4 \mathrm{SD})$ \\
\hline Participated in mandatory TA training course & 3 & 2 & 3 & 1 & 0 \\
\hline
\end{tabular}

by the drive of the individual students to build those experiences for themselves.

\section{TA Experience, Time in Program, and Career Goals Do Not Appear to Be Important Factors in Adoption of EBT Strategies}

We sought to identify whether there were trends in experiences among participants who stopped or continued progressing toward EBT adoption at particular stages in the DOI model. Those who had progressed further toward adopting EBT tended to have been in their programs for longer and had more TA experience (Table 3), but low sample sizes and high standard deviations for these numbers suggest that these are supporting rather than defining factors of EBT adoption. There was no indication that participation in a mandatory TA training had a positive impact on adoption of EBT-in fact, very few of the participants who progressed to the final stages of the model had taken a mandatory TA training course (Table 3). We also examined whether experience with BER (either as the primary focus of their $\mathrm{PhD}$ or supplemental to their primary research focus), correlated with progression toward EBT adoption. While all seven participants with BER experience had decided to implement EBT strategies, only one reached the Confirmation stage, indicating that participation in BER was not necessarily a factor facilitating progression through the DOI model.

There was no indication that having an interest in EBT corresponded to specific career goals, although participants who indicated that they would seek teaching-only academic positions all knew about EBT and had at least decided to use EBT strategies in the future (Figure 3). Graduate students who reached the Implementation and Confirmation stages were not strictly focused on a career in teaching - several were interested in primarily research positions or in leaving academia. Only one participant who indicated interest in a position that balanced both research and teaching responsibilities did not have knowledge of EBT strategies (Figure 3).

\section{DISCUSSION}

In this research, we used a well-established theory to describe the adoption of an innovation (EBT) by a novel study group (graduate students). The DOI model is a useful tool to understand where graduate students may be in the process of adopting EBT, which allows us to identify where graduate students may encounter barriers to EBT adoption. To our knowledge, this is the first study to broadly investigate graduate student perceptions of EBT at institutions across the United States, providing insight into the graduate student-level variables that likely impact TA implementation of EBT into current undergraduate classrooms.

Just under half of our graduate students reported participating in a mandatory boot camp TA training, a figure comparable to results of a national survey reporting on the types of professional development offered to graduate students. In the survey, $45 \%$ of participating institutions reported availability of a short presemester professional development training at the institutional level, and $51 \%$ at the departmental level (Schussler et al., 2015). However, in the same survey, only $23 \%$ of respondents reported that instructional techniques were not addressed in their professional development programs, which contrasts with the $44 \%$ of our participants who

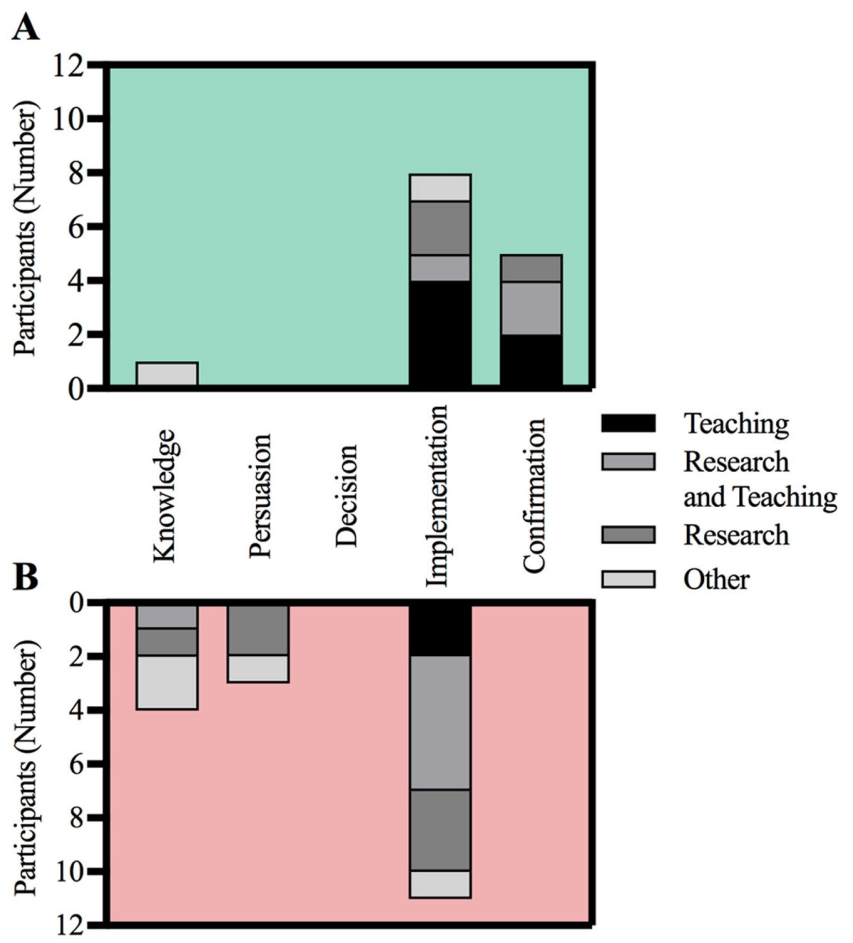

FIGURE 3. Participants at different stages in the DOI model had varied career goals, though all participants who were primarily interested in teaching reached the Implementation stage. (A) The career goals of participants who are in the process of progressing through the model are represented in the top graph (green). (B) Career goals of participants who have dropped out and stopped progressing through the DOI model are in the lower graph (red). 
reported that no instructional techniques were taught in their mandatory professional development training. Our finding that graduate students themselves are aware of the dearth of opportunities and support offered to develop their instructional skills is in line with other reports on graduate student perceptions (Austin, 2002; Schussler et al., 2015): when asked what graduate students would change about their professional development training, 39\% requested additional pedagogical training, and 10\% desired faculty acknowledgment of the value of professional development training (Schussler et al., 2015).

None of our participants described receiving substantial training in instructional strategies via a boot camp-style training (Figure 1B), and there did not seem to be a correlation between participation in boot camp training and adoption of EBT (Table 3). This may not be surprising, given recent data describing the inadequacy of boot camp training in providing significant long-term benefits for graduate students (Feldon et al., 2017). Additionally, a review of several studies assessing training interventions found that onetime workshops do not seem to be effective; and successful strategies lasted at least 4 weeks-and often longer (Henderson et al., 2011). However, training courses by themselves do not appear to be drivers of EBT adoption among our participants: several who reported participating in such training courses had made little progress toward adopting EBT, and none of the graduate students in our sample who adopted EBT, as described by the DOI model, had participated in a full mandatory TA training course at their institutions. Even term-long TA training courses may be insufficient in duration to incite long-term change-a recent study on a term-long intervention designed to promote TA adoption of EBT strategies did not result in consistent use of EBT by participants (Becker et al., 2017), and a survey of 1500 graduate students found that engagement in teaching development activities for less than 30 hours did not significantly impact participant's longterm self-efficacy in teaching (Connolly et al., 2018). To better support graduate students in gaining fluency with EBT strategies, departments will want to consider the research literature on change strategies that result in anticipated outcomes (Henderson et al., 2011).

Previous recommendations for teaching development emphasize the importance of intensive and ongoing training that encourages TAs to reflect on their teaching (Schussler et al., 2008). Gardner and Jones (2011) echo this and additionally stress that formalized professional development training reinforces the perception that the institution values teachingcontrary to the climate of lip service to teaching that $28 \%$ of our sample indicated perceiving at their institutions. Building an institutional culture that supports and values teaching is more likely to motivate graduate students and faculty to prioritize their instructional roles (Gardner and Jones, 2011; Dennin et al., 2017). Further, we found that the graduate students who felt as though they were part of the changing landscape of academia (Table 2), and thus engaged in supporting and promoting EBT, were also the students who were progressing furthest in the DOI model. We recommend that institutions capitalize on these potential change-makers by engaging graduate students in institutional efforts to build a supportive climate around EBT. It seems likely that recruiting graduate students to participate or help lead activities such as workshops in using EBT strategies could help the students involved, their peers, and perhaps even current faculty to further adopt EBT.

In light of national efforts to improve undergraduate life science classrooms, it is encouraging that graduate students express interest in investing in instructional training and appear to be largely aware of and interested in using EBT. Perhaps surprisingly, we did not detect that a graduate student's advisor played a significant role in his or her interest or investment in EBT in either a positive or negative direction. Because graduate students represent the pool of future faculty, their apparent willingness to use EBT suggests that future faculty may be open to embracing EBT strategies, perhaps in ways their mentors have not. Despite this, the majority of our participants had not actually implemented EBT strategies and therefore were unable to complete the process of adoption as described by the DOI model. There are many possible explanations for the relatively low reported implementation despite high interest in EBT. Some participants may not be receiving training in these skills (as reported), while others described lacking opportunities and/or enough autonomy to enable them to incorporate EBT into their classrooms. These deficits could possibly be addressed by engaging graduate students in the process of building supportive institutional cultures toward EBT, as described earlier. A deeper understanding of conditions that promote or prevent graduate student adoption of EBT will require research on the relevant contextual variables as well as impacts of professional development programs (Reeves et al., 2016).

Graduate students who seek out EBT experiences are progressing further through the process of EBT adoption than those who only partake in mandatory teaching requirements. The ramifications of this could be that graduate students who are unaware of (or uninterested in) the shift toward EBT may be missing important opportunities in their professional development, which could make them less competitive applicants if they aspire toward academic careers. Graduate students who are interested in teaching positions or even research positions in which they will inevitably have teaching responsibilities may be at a disadvantage if they do not have adequate support, training, and opportunities to develop EBT skills (Austin, 2002; Gardner and Jones, 2011; Reeves et al., 2016).

The graduate students in our sample who are gaining experiences that prepare them for a career in teaching were more likely to seek out such opportunities on their own and are largely self-aware of their role in the shift in academia that values effective undergraduate biology education. It seems possible that the graduate students who are adopting EBT strategies are also the students driving change at their institutions and encouraging a culture that values EBT. Graduate students rely on and value support from their peers (Austin, 2002), and more research on how these students may be acting as agents of change among their peers could uncover paths to supporting and leveraging these change-makers. To more fully understand a graduate student's likelihood of not just adopting and implementing EBT, but also of being a leader in effecting systemic change, we suggest that further interview studies and national longitudinal surveys be conducted. These studies should focus on triangulating the relationship 
between participants' experiences in their graduate programs, their attitudes toward teaching, and their plans to implement EBT themselves should they have the opportunity in their future. Such studies could be informed by our data indicating that, at least in this sample, graduate students value contemporary EBT strategies, even if those surrounding them are not yet on board.

\section{LIMITATIONS}

While our study is limited by a relatively small sample size, our participants appear representative of nationwide biology graduate students in distributions of gender, race and ethnicity, and institution type. Because participants volunteered for interviews after completing a survey about their experiences with EBT strategies, our participant sample is subject to bias in favor of those interested in supporting research and promotion of EBT and may not reflect the general population of life science graduate students. While the majority of our participants did have positive attitudes toward EBT strategies, our sample also included several participants who were largely unaware of and uninterested in EBT, indicating that our sampling did not impede our ability to reach participants with diverse experiences and perceptions of EBT.

Additionally, there are many factors that could impact the rate of adoption of EBT that we were unable to address through our study. Rogers's original DOI model highlights prior conditions as factors that impact the rate of adoption of an innovation (Rogers, 2003). For graduate students, these prior conditions could include their level of satisfaction with instructor-centered teaching strategies, their training in the use of EBT strategies, their perception of the need to introduce diverse teaching strategies that can positively impact minority students, and the acceptance and use of EBT within their programs at their universities. While some of these factors were addressed in the interviews, we do not attempt to robustly characterize how these complex experiences and beliefs impact our participants' rate of progression through the model.

\section{CONCLUSIONS}

Given the increasing prevalence of EBT in undergraduate biology classrooms, we are encouraged that the majority of graduate students in our sample value and show interest in evidence-based training, and it seems promising that at least some future life science faculty indeed plan to implement EBT strategies in their classroom. However, it is clear that these students are not generally satisfied with the support they receive from their programs in developing teaching skills. Further, it does not seem equitable that graduate students must seek out training and experiences beyond what is required of them in order to gain pertinent professional development. It follows that students who are not taking these extra steps will potentially be underprepared as candidates for job opportunities that involve teaching. To address this disparity, we must continue learning from education research and graduate students themselves, leveraging their perspectives and using best practices in training to establish effective support such that future faculty can confidently and efficaciously teach in higher education.

\section{ACKNOWLEDGMENTS}

This work would not be possible without the graduate student participants who generously volunteered to share their thoughts and experiences. We also thank members of the Biology Education Research Lab at Portland State University for their helpful feedback on our data analysis and early drafts of the manuscript. Finally, we thank the two anonymous reviewers for their very constructive feedback and suggestions.

\section{REFERENCES}

American Association for the Advancement of Science. (2011). Vision and change in undergraduate biology education: A call to action. Washington, DC.

Andrews, T. C., \& Lemons, P. P. (2015). It's personal: Biology instructors prioritize personal evidence over empirical evidence in teaching decisions. CBE-Life Sciences Education, 14(1), ar7.

Austin, A. E. (2002). Preparing the next generation of faculty: Graduate school as socialization to the academic career. Journal of Higher Education, 73(1), 94-122.

Becker, E. A., Easlon, E. J., Potter, S. C., Guzman-Alvarez, A., Spear, J. M., Facciotti, M. T., ... Pagliarulo, C. (2017). The effects of practice-based training on graduate teaching assistants' classroom practices. CBE-Life Sciences Education, 16(4), ar58.

Bhattacherjee, A. (2001). Understanding information systems continuance: An expectation-confirmation model. MIS Quarterly, 25(3),351-370.

Brownell, S. E., \& Tanner, K. D. (2012). Barriers to faculty pedagogical change: Lack of training, time, incentives, and... tensions with professional identity? CBE-Life Sciences Education, 11(4), 339-346.

Cleveland, L. M., Olimpo, J. T., \& DeChenne-Peters, S. E. (2017). Investigating the relationship between instructors' use of active-learning strategies and students' conceptual understanding and affective changes in introductory biology: A comparison of two active-learning environments. CBE-Life Sciences Education, 16(2), ar19

Cohen, D., \& Crabtree, B. (2006). Qualitative Research Guidelines Project. Retrieved October 18, 2017, from www.qualres.org/HomeSemi-3629 html

Connolly, M. R., Lee, Y.-G., \& Savoy, J. N. (2018). The effects of doctoral teaching development on early-career STEM scholars' college teaching self-efficacy. CBE-Life Sciences Education, 17(1), ar14.

Creswell, J. W. (2009). Research design: Qualitative, quantitative, and mixed methods approaches (3rd ed.). Thousand Oaks, CA: Sage.

Dennin, M., Schultz, Z. D., Feig, A., Finkelstein, N., Greenhoot, A. F., Hildreth, M., ... O'Dowd, D. K. (2017). Aligning practice to policies: Changing the culture to recognize and reward teaching at research universities. CBELife Sciences Education, 16(4), es5.

Dobbins, M., Ciliska, D., Cockerill, R., Barnsley, J., \& DiCenso, A. (2002). A framework for the dissemination and utilization of research for healthcare policy and practice. Worldviews on Evidence-Based Nursing, 9(1), 149-160.

Feldon, D. F., Jeong, S., Peugh, J., Roksa, J., Maahs-Fladung, C., Shenoy, A., \& Oliva, M. (2017). Null effects of boot camps and short-format training for PhD students in life sciences. Proceedings of the National Academy of Sciences USA, 114(37), 9854-9858.

Freeman, S., Eddy, S. L., McDonough, M., Smith, M. K., Okoroafor, N., Jordt, H., \& Wenderoth, M. P. (2014). Active learning increases student performance in science, engineering, and mathematics. Proceedings of the National Academy of Sciences of the USA, 111(23), 8410-8415. doi: 10.1073/pnas.1319030111

Gardner, G. E., \& Jones, M. G. (2011). Pedagogical preparation of the science graduate teaching assistant: Challenges and implications. Science Educator, 20(2), 31.

Gormally, C., Sullivan, C. S., \& Szeinbaum, N. (2016). Uncovering barriers to teaching assistants (TAs) implementing inquiry teaching: Inconsistent facilitation techniques, student resistance, and reluctance to share control over learning with students. Journal of Microbiology \& Biology Education, 17(2), 215. 
Handelsman, J., Ebert-May, D., Beichner, R., Bruns, P., Chang, A., DeHaan, R., ... Tilghman, S. M. (2004). Scientific teaching. Science, 304(5670), 521-522.

Henderson, C., Beach, A., \& Finkelstein, N. (2011). Facilitating change in undergraduate STEM instructional practices: An analytic review of the literature. Journal of Research in Science Teaching, 48(8), 952-984.

Henderson, C., \& Dancy, M. H. (2008). Physics faculty and educational researchers: Divergent expectations as barriers to the diffusion of innovations. American Journal of Physics, 76(1), 79-91.

Henderson, C., Dancy, M., \& Niewiadomska-Bugaj, M. (2012). Use of research-based instructional strategies in introductory physics: Where do faculty leave the innovation-decision process? Physical Review Special Topics-Physics Education Research, 8(2), 020104.

Indiana University Center for Postsecondary Research. (2017). Carnegie Classification of Institutions of Higher Education. Retrieved July 8, 2017, from http://carnegieclassifications.iu.edu

Kajermo, K. N., Nordström, G., Krusebrant, Å., \& Björvell, H. (1998). Barriers to and facilitators of research utilization, as perceived by a group of registered nurses in Sweden. Journal of Advanced Nursing, 27(4), 798807.

Kendall, K. D., Niemiller, M. L., Dittrich-Reed, D., Chick, L. D., Wilmoth, L., Milt, A., ... Rubio, L. (2013). Departments can develop teaching identities of graduate students. CBE-Life Sciences Education, 12(3), 316-317.

Kurdziel, J. P., Turner, J. A., Luft, J. A., \& Roehrig, G. H. (2003). Graduate teaching assistants and inquiry-based instruction: Implications for graduate teaching assistant training. Journal of Chemical Education, 80(10), 1206.

Luft, J. A., Kurdziel, J. P., Roehrig, G. H., \& Turner, J. (2004). Growing a garden without water: Graduate teaching assistants in introductory science laboratories at a doctoral/research university. Journal of Research in Science Teaching, 41(3), 211-233.

Lund, T. J., \& Stains, M. (2015). The importance of context: An exploration of factors influencing the adoption of student-centered teaching among chemistry, biology, and physics faculty. International Journal of STEM Education, 2(1), 13.

Madill, A., Jordan, A., \& Shirley, C. (2000). Objectivity and reliability in qualitative analysis: Realist, contextualist and radical constructionist epistemologies. British Journal of Psychology, 91(1), 1-20.

Michael, J. (2006). Where's the evidence that active learning works? Advances in Physiology Education, 30(4), 159-167.

Mutambuki, J. M., \& Schwartz, R. (2018). We don't get any training: The impact of a professional development model on teaching practices of chemistry and biology graduate teaching assistants. Chemistry Education Research and Practice, 19, 106-121.
National Science Foundation (NSF). (2016a, updated December 2017). Survey of Earned Doctorates. Retrieved February 27, 2018, from www.nsf.gov/ statistics/2018/nsf18304/datatables/tab57.html

NSF. (2016b, updated August 2017). Survey of Graduate Students and Postdoctorates in Science and Engineering. Retrieved February 27, 2018, from https://ncsesdata.nsf.gov/gradpostdoc/2016/index.html

Park, C., \& Ramos, M. (2002). The donkey in the department? Insights into the graduate teaching assistant (GTA) experience in the UK. Journal of Graduate Education, 3(2), 47-53.

President's Council of Advisors on Science and Technology. (2012). Engage to excel: Producing one million additional college graduates with degrees in science, technology, engineering, and mathematics. Washington, DC: U.S. Government Office of Science and Technology. Retrieved September 25, 2017, from https://eric.ed.gov/?id=ED541511

Reeves, T. D., Marbach-Ad, G., Miller, K. R., Ridgway, J., Gardner, G. E., Schussler, E. E., \& Wischusen, E. W. (2016). A conceptual framework for graduate teaching assistant professional development evaluation and research. CBE-Life Sciences Education, 15(2), es2.

Rogers, E. M. (2003). Diffusion of innovations (p. 551). New York: Free Press.

Rushin, J. W., De Saix, J., Lumsden, A., Streubel, D. P., Summers, G., \& Bernson, C. (1997). Graduate teaching assistant training: A basis for improvement of college biology teaching and faculty development? American Biology Teacher, 59(2), 86-90

Schussler, E., Torres, L. E., Rybczynski, S., Gerald, G. W., Monroe, E., Sarkar, P., ... Osman, M. A. (2008). Transforming the teaching of science graduate students through reflection. Journal of College Science Teaching, 38(1), 32.

Schussler, E. E., Read, Q., Marbach-Ad, G., Miller, K., \& Ferzli, M. (2015). Preparing biology graduate teaching assistants for their roles as instructors An assessment of institutional approaches. CBE-Life Sciences Education, 14(3), ar31.

Shortlidge, E. E., \& Eddy, S. L. (2018). The trade-off between graduate student research and teaching: A myth? PLOS ONE 13(6), e0199576.

Springer, L., Stanne, M. E., \& Donovan, S. S. (1999). Effects of small-group learning on undergraduates in science, mathematics, engineering, and technology: A meta-analysis. Review of Educational Research, 69(1), 21-51.

Sundberg, M. D., Armstrong, J. E., \& Wischusen, E. W. (2005). A reappraisal of the status of introductory biology laboratory education in US colleges $\&$ universities. American Biology Teacher, 67(9), 525-529.

Tanner, K. D. (2013). Structure matters: Twenty-one teaching strategies to promote student engagement and cultivate classroom equity. CBE-Life Sciences Education, 12(3), 322-331. 